\title{
2015 and Beyond: Usable and Unbiased Data
}

The American Association for Respiratory Care has conducted 3 conferences since March 2008, to picture the future practice of respiratory care. The focus of the first conference was to create a foundation and vision for the profession by examining expected changes in healthcare and how this may impact the respiratory therapist in the year 2015 and beyond. Topics explored were disease management, biomedical innovation, and human resource issues, as the United States adjusts to population increase, the aging of America, and decreasing the cost of healthcare while maintaining or improving quality. ${ }^{1}$ The second conference in April 2009 focused on the competencies needed by graduate respiratory therapists and the workforce as the profession adjusts to these projected changes. ${ }^{2}$ The third conference, held in July 2010, sought to determine how the respiratory therapy (RT) education system (both before and after degree) needs to change in order for the competencies required of the future RT workforce to be accomplished with minimal impact on current personnel. $^{3}$

See the Original Study on Page 1906

In this issue of Respiratory CARE, Barnes et al present findings from their survey of program directors of RT education programs regarding the ability of their current infrastructure to make any necessary changes to meet the changing needs for competent RT providers in the future. ${ }^{4}$ These findings were used as background information to ascertain the required length of RT programs and future needs of currently practicing respiratory therapists at the third conference.

While there are many opinions regarding what the respiratory therapist of the future should do or look like, there is a noted lack of peer-reviewed research to guide the profession as we look into the future. Opinions are quite passionate, as witnessed at the open hearing after the third conference in July 2010 and other forums where 2015 and Beyond updates have been presented. For this study, ${ }^{4}$ Barnes and his co-authors invited all 435 RT education program directors listed by the Commission on Accreditation for Respiratory Care to participate in an Internetbased survey. Response rates for Internet surveys are typically low, ${ }^{5}$ but Barnes et al had an excellent response rate of $80 \%$. This speaks to the notion that a lot of people have something to say regarding this issue. Given the interest (and emotion) for this topic, some readers of this study will discern that the data are valid and useful, while others will believe that the data are misleading and the intent is to publish befuddling misinformation. Whatever your opinion, future researchers must carefully select methods similar to the one used in this study in order to add usable and unbiased data to the literature.

The instrument used by Barnes et al was designed and reviewed for face validity by the 2015 Research Group. The survey was pilot-tested (I was among those asked to take the pilot survey), and approved by the institutional review board of Northeastern University. Most of the responses were from associate-degree programs, which is expected since most of the RT education programs are at the associate level. Answers collected in survey research always contain some amount of error, and a perfectly accurate survey is seldom, if ever, conducted. ${ }^{6}$ Also, Internet-based surveys often have high non-response errors, as answers are overlooked or omitted by the respondents. In the Barnes et $\mathrm{al}^{4}$ survey many questions were left unanswered, indicating that a program did not teach a particular competency. No follow-up was conducted to verify if this was the reason, but it opens the question of why some did not provide answers.

Did the respondents believe that their survey answers would be used to support a predetermined objective the authors felt to be true? Or were the questions not answered because the respondent did not want the survey administrators to know that his or her RT program is deficient in certain competencies and will not have the resources necessary to be able to change to meet accreditation or community requirements? Other explanations may be that courses are not taught uniformly across RT programs because of time constraints, or the length of the program does not allow time to teach any additional competencies.

Nonetheless, Barnes et al were able to determine from the findings that many programs, regardless of the degree awarded, do not teach the majority of the competencies identified in the second 2015 and Beyond conference. Yet many may believe this is not the complete picture or a fair assessment. More information would be helpful in order to make the next best steps regarding transitioning the profession.

As noted by Barnes et $\mathrm{al},{ }^{4}$ it is difficult to interpret a selective lack of response, but they do conclude that, de- 


\section{AND BEYOND: UsABLE AND UNBIASED}

spite the limitations of the responses received, important statistically significant differences do exist between the associate and baccalaureate programs. The baccalaureate programs cover more of the competencies identified in the second 2015 and Beyond conference than do the associate programs, including research, applying evidenced in clinical practice, healthcare policy, and advanced practice models. Also noteworthy is the consensus on 2 items, by both baccalaureate and associate program directors, that the RRT credential (instead of the CRT credential) should be required for professional practice, and there was broad support for the idea that a baccalaureate or graduate degree should be required of future graduates after they enter practice. The results show that there are areas where both associate-degree and baccalaureate-degree programs can work together to transition students to 2015 and Beyond.

I highly commend Barnes et al for attempting to glean this important information. Their answers are usable and unbiased, given their conclusions. However, as mentioned before, there is a serious lack of peer-reviewed research on this subject, and surveys need to be administered with rigor so that respondents and readers can easily judge for themselves whether the questions and answers are valid (through construct validity-the instrument actually measures the intended construct) and reliable (the extent to which answers are consistent over time). The opinions are quite passionate, but best practices for implementation should be used in any future survey design, sampling, solicitation, and interpretation. Again, I encourage RESPIRATORY CARE readers to become familiar with best practices for survey methods and to conduct education survey research such as this study by Barnes and his co-authors to add to the literature that will provide meaningful guidance

The author has disclosed no conflicts of interest.

Correspondence: Lynda T Goodfellow EdD RRT AE-C FAARC, Byrdine F Lewis School of Nursing and Health Professions, Georgia State University, PO Box 3995, Atlanta GA 30302. E-mail: 1tgoodfellow@ gsu.edu.

DOI: $10.4187 /$ respcare.01619 to our profession as we navigate our future in these uncertain healthcare times.

Just as Giordano opined earlier this year, ${ }^{7}$ I suggest that one review the papers that describe the 3 conferences and carefully ask if our education system is able to prepare graduates with the expanded skills inventory identified in the second conference. The more important question is, however, are we ready for 2015? And, finally, can we provide a transition plan to get us from today to 2015 and Beyond? After 3 years of work with conference planning, manuscript writing, and Internet-based surveys, is our profession able (or willing) to transition from where we are today to where we will need to be tomorrow? Our future patients and students deserve a valid answer to this question.

Lynda T Goodfellow EdD RRT AE-C FAARC Byrdine F Lewis School of Nursing and Health Professions Division of Respiratory Therapy Georgia State University Atlanta, Georgia

\section{REFERENCES}

1. Kacmarek RM, Durbin CG, Barnes TA, Kageler WV, Walton JR, O'Neil EH. Creating a vision for respiratory care in 2015 and beyond. Respir Care 2009;54(3):375-389.

2. Barnes TA, Gale DD, Kacmarek RM, Kageler WV. Competencies needed by graduate respiratory therapists in 2015 and beyond. Respir Care 2010;55(5):601-616.

3. Barnes TA, Kacmarek RM, Kageler WV, Morris MJ, Durbin CG. Transitioning the respiratory therapy workforce for 2015 and beyond. Respir Care 2011;56(5):681-690.

4. Barnes TA, Kacmarek RM, Durbin CG. Survey of respiratory therapy education program directors in the United States. Respir Care 2011;56(12):1906-1915.

5. de Leeuw E. Choosing the method of data collection. In: de Leeuw E, Hox JJ, Dillman DA, editors. International handbook of survey methodology. New York: Lawrence Erlbaum Associates; 2008:113135.

6. Hox JJ. Accommodating measurement errors. In: de Leeuw E, Hox JJ, Dillman DA, editors. International Handbook of Survey Methodology. New York: Lawrence Erlbaum Associates; 2008:387-402.

7. Giordano SP. Building a bridge to the future: Some points to ponder. Respir Care 2011; 56(5):720-721. 